\title{
Rendimentos de grãos, seus componentes e características morfológicas do fejoeiro comum cultivado em quatro densidades de semeadura na safrinha ${ }^{1}$
}

\author{
Grain yield, components and morphologial traits of common bean \\ in four sowing densities in the latter season
}

\author{
Adilson Jauer ${ }^{2}$ Luiz Marcelo Costa Dutra ${ }^{3}$ Orlando Antônio \\ Lucca Filho $^{4}$ Antônio Luis Santi ${ }^{2}$ Licio Zabot ${ }^{5}$ Daniel Uhry $^{6}$ \\ Rafael Bonadimam ${ }^{7}$ Gustavo Luiz Bellé ${ }^{8}$ Alessandro Dal'Col \\ Lúcio ${ }^{9}$
}

\section{RESUMO}

A cultivar de feijoeiro comum Iraí, tipo I, foi cultivada durante a safrinha de 2001 em Santa Maria-RS, em quatro populações de plantas (200, 300, 400 e 500 mil plantas ha $\left.\mathrm{h}^{-1}\right)$. $O$ delineamento experimental utilizado foi o de blocos ao acaso com quatro repetições. Foram avaliados o rendimento de grãos, os componentes do rendimento e algumas características morfológicas. Não houve diferença no rendimento de grãos, no número de legumes $\mathrm{m}^{-2}$, número de grãos legume $e^{-1}$, peso médio de 100 grãos e estatura de planta entre as populações testadas.

Palavras-chave: Phaseolus vulgaris L., tipo I, feijão, populações de plantas, safrinha.

\section{ABSTRACT}

The common bean cultivar Irai, type I, was grown during the latter season of 2001 in Santa Maria-RS, in four plant populations $(200,300,400$, and 500 thousand plants $\left.h \mathrm{a}^{-1}\right)$. The experiment design used randomized blocks with four replications. The grain yield, yield components and some morphological traits were evaluated. There were no significant differences among populations in grain yield, number of pods $m^{-2}$, number of grains pod $^{-1}$, average weight of hundred grains, and plant high.

Key words: Phaseolus vulgaris L., type I, beans, plant population, latter season.

\section{INTRODUÇ̃̃O}

O Rio Grande do Sul apresenta duas épocas de cultivo do feijoeiro: a safra, semeada de agosto a outubro, e a safrinha, semeada de janeiro a fevereiro, sendo que entre ambas existem diferenças climáticas sensíveis no que se refere à temperatura do ar, do solo e disponibilidade hídrica.

Uma das primeiras práticas a ser adotada ao estudar a adaptação de uma espécie a uma condição de cultivo é o arranjo de plantas, pela alteração que proporciona no microclima, na disponibilidade de luz, nutrientes, água, temperatura, etc. Ocorre que todo

\footnotetext{
${ }^{1}$ Parte da dissertação de mestrado do primeiro autor, como requisito parcial para obtenção do título de Mestre em Agronomia.

${ }^{2}$ Engenheiro Agrônomo, Aluno do Curso de Pós-graduação em Agronomia-Universidade Federal de Santa Maria (UFSM), Bolsista CAPES.

${ }^{3}$ Engenheiro Agrônomo, Dr. Professor Adjunto, Departamento de Fitotecnia, (UFSM), 97105-900, Santa Maria, RS. Autor para correspondência: E-mail marcelo@ccr.ufsm.br.

${ }^{4}$ Engenheiro Agrônomo, Prof. Adjunto, Dr. Departamento de Fitotecnia- Universidade Federal de Pelotas (UFPel).

${ }^{5}$ Aluno do curso de Agronomia-UFSM, Bolsista CNPq

${ }^{6}$ Aluno do Cólégio Agrícola de Santa Maria-UFSM.

${ }^{7}$ Aluno do curso de Agronomia-UFSM, bolsista FIPE.

${ }^{8}$ Aluno do curso de Agronomia-UFSM.

${ }^{9}$ Engenheiro Agrônomo, Dr. Professor Adjunto, Departamento de Fitotecnia, UFSM.
} 
pacote tecnológico hoje indicado foi desenvolvido por pesquisas, em sua imensa maioria, realizadas durante a safra. Pela falta de pesquisa para esta segunda época de cultivo, os produtores têm utilizado as mesmas recomendações de práticas culturais da primeira época.

$O$ aumento da produção através da utilização de altas populações pode ser conseguido nas cultivares de hábito determinado (CROTHERS \& WESTERMANN,1977). MASCARENHAS etal. (1966), LEAKEY (1972), Maulk et al. (1973) apud THOMÉ (1982), também afirmaram que o uso de populações mais elevadas para cultivares de hábito determinado resultam em maiores produções.

Em plantas dos tipos I, II e III tanto o rendimento de grãos, como algumas características morfológicas (número de ramificações planta ${ }^{-1}$, número de nós ramificação $\mathrm{o}^{-1} \mathrm{e}$ número nós $\mathrm{m}^{-2}$ ) foram afetados significativamente pela densidade populacional (NIENHUIS \& SING, 1985).

THOMÉ (1982), trabalhando com a cultivar Iraí, observou aumento no número de ramificações $\mathrm{m}^{-2}$ quando a densidade aumentou de 300 para 700 mil plantas ha ${ }^{-1}$, sendo que a população de 300 mil plantas ha $^{-1}$ não diferiu da de 500 mil plantas ha ${ }^{-1}$. O número de ramificações planta ${ }^{-1}$ comportou-se de maneira inversa, sendo os maiores valores encontrados nas densidades mais baixas, fato esse, explicado pelo autor, como sendo devido à menor competição por luz, água e nutrientes nas menores densidades. Já o número de nós planta ${ }^{-1}$ se manteve inalterado, parecendo ser esta uma característica estável das cultivares de hábito determinado. Ospina (s.d.), apud THOMÉ (1982), coloca que o número de nós do caule pode ser considerada como uma característica de pouca variação para as plantas com o mesmo material genético, desde que em condições similares de meio.

O presente trabalho teve como objetivo determinar a população de plantas que assegure o maior rendimento de grãos da cultivar de feijoeiro comum Iraí, tipo I, na safrinha, e observar as variações nos componentes do rendimento e em algumas das características morfológicas provocadas pelas densidades testadas.

\section{MATERIAL EMÉTODOS}

O experimento foi conduzido na área do Departamento de Fitotecnia no Campus da Universidade Federal de Santa Maria, no município de Santa Maria-RS, região climática da Depressão Central, a uma altitude de $95 \mathrm{~m}$, latitude $29^{\circ} 42^{\prime} 24^{\prime \prime}$ S e longitude $53^{\circ} 48^{\prime} 42^{\prime \prime} \mathrm{W}$.

O clima da região, segundo a classificação de KÖEPPEN (MORENO, 1961) é do tipo Cfa - temperado chuvoso, com chuvas bem distribuídas ao longo do ano e subtropical do ponto de vista térmico. A temperatura média normal do mês mais quente ocorre em janeiro $\left(24,6^{\circ} \mathrm{C}\right)$ e a do mês mais frio em junho $\left(12,9^{\circ} \mathrm{C}\right)$. Quanto à média normal das máximas, esta é de $30,4^{\circ} \mathrm{C}$ (janeiro) e de $19,2^{\circ} \mathrm{C}$ em junho. A média das temperaturas mínimas do mês mais quente é $18,7^{\circ} \mathrm{C}$ em dezembro e $9,3^{\circ} \mathrm{C}$ a do mês mais frio em junho (Brasil, 1992). A temperatura média na safra (semeadura de agosto a outubro) para Santa Maria, apresenta-se em elevação, em agosto com $15,0^{\circ} \mathrm{C}$ e dezembro indo a $23,6^{\circ} \mathrm{C}$, enquanto na safrinha (semeadura em janeiro e fevereiro), o comportamento é inverso, sendo a maior temperatura em janeiro com $24,8^{\circ} \mathrm{C}$ e a menor em maio com $16,6^{\circ} \mathrm{C}$ (Dados obtidos da estação Meteorológica da Universidade Federal de Santa Maria em 30 anos).

$\mathrm{O}$ solo pertence à Unidade de Mapeamento São Pedro sendo classificado no Sistema Brasileiro de Classificação de Solos (EMBRAPA, 1999) como ARGISSOLO VERMELHO distrófico arénico.

A correção do solo e a adubação da área foi feita de acordo com os resultados da análise de solo, em concordância com as recomendações da ROLAS (1994) para a cultura do feijoeiro, utilizando 4,8 toneladas ha ${ }^{-1}$ de calcário PRNT $100 \%$ e $450 \mathrm{~kg} \mathrm{ha}^{-1}$ da formulação 5-20-20 na semeadura. O calcário foi aplicado quatro meses antes da semeadura.

A cultivar utilizada foi a Iraí, nas densidades de semeadura de 200.000, 300.000, 400.000 e 500.000 plantas $\mathrm{ha}^{-1}$, espaçadas de $0,40 \mathrm{~m}$ entre linhas.

O delineamento experimental utilizado foi o de blocos ao acaso com quatro repetições. As parcelas foram constituídas de oito linhas com $8,0 \mathrm{~m}$ comprimento, espaçadas $0,4 \mathrm{~m}$, com área total de $25,6 \mathrm{~m}^{2}$. A área útil constituiu-se de duas linhas descontando $1,0 \mathrm{~m}$ nas extremidades como bordadura, perfazendo uma área de $4,8 \mathrm{~m}^{2}$.

Para a semeadura, foi feita a contagem manual das sementes para cada linha com sua respectiva densidade de semeadura corrigida para o poder germinativo de $100 \%$ mais $5 \%$, para obter a densidade de plantas desejada, sendo a semeadura realizada dia 21 de fevereiro de 2001. A emergência das plantas foi considerada quando, aproximadamente, $50 \%$ das plântulas haviam emergido, aos seis dias após a semeadura. Aos 17 dias após a emergência, foi realizada adubação de cobertura com $80 \mathrm{~kg} \mathrm{ha}^{-1}$ de nitrogênio na forma de uréia. Foram executadas todas as práticas culturais recomendadas para controle de insetos, moléstias e plantas daninhas.

Em cada parcela, por ocasião da colheita ( 76 dias após a emergência), foram amostradas 0,50 metro linear da área útil para as seguintes determinações: medidas da distância da base do primeiro legume ao 
solo , medidas da distância da inserção do primeiro legume ao solo, estatura de plantas, número de grãos legume $^{-1}$, número de legumes planta ${ }^{-1}$, número de legumes $\mathrm{m}^{2}$, número de nós da haste principal planta ${ }^{-1}$, número de ramos planta ${ }^{-1}$, número de ramos $\mathrm{m}^{-2} \mathrm{e}$ peso de 100 grãos $(\mathrm{g})$.

Para análise do rendimento, as plantas da área útil foram arrancadas e posteriormente trilhadas em trilhadeira estacionária. Os grãos limpos foram pesados e foi feita a determinação do teor de umidade, após então calculado o rendimento $\mathrm{em} \mathrm{kg} \mathrm{ha}^{-1} \mathrm{com}$ correção do peso para a umidade de $13 \%$.

A análise estatística dos dados foi realizada através de análise da variância e teste de hipóteses para verificar a significância da interação e dos efeitos principais. Caso fosse significativa, realizou-se análise da regressão (STORCK \& LOPES, 1998), com auxílio do programa estatístico SOC (EMBRAPA, 1986).

Os dados de temperatura, precipitação e evapotranspiração foram obtidos da estação meteorológica do Departamento de Fitotecnia, localizada no Campus da Universidade Federal de Santa Maria.

\section{RESULTADOS E DISCUSSÃO}

Não foram detectadas diferenças significativas para o rendimento de grãos, sendo que a média do experimento foi de $1958 \mathrm{~kg} \mathrm{ha}^{-1}$ (Tabela 1), próximo ao máximo rendimento encontrado na literatura para a cultivar, que foi de $2200 \mathrm{~kg} \mathrm{ha}^{-1}$ (MARTINOTTO et al., 1982). Estes resultados demonstram a viabilidade da semeadura desta cultivar na safrinha, com a adequação das práticas culturais.

Estes dados concordam com os encontrados por THOMÉ (1982), o qual não detectou diferenças significativas para o rendimento de 300 a 700 mil plantas ha ${ }^{-1}$ em três épocas de semeadura realizadas durante o período da safra. No entanto, este autor observou rendimentos que variaram de 1100 a $550 \mathrm{~kg} \mathrm{ha}^{-1}$ devido ao excesso de precipitação e ao elevado ataque de antracnose.

As condições climáticas durante o período vegetativo da cultura apresentaram uma temperatura média de $26,7^{\circ} \mathrm{C}$, precipitação média de $4,84 \mathrm{~mm} \mathrm{dia}^{-1} \mathrm{e}$ evapotranspiração média de $3,36 \mathrm{~mm} \mathrm{dia}^{-1}$. Para todo o ciclo da cultura a temperatura média foi de $21,4^{\circ} \mathrm{C}$, precipitação média de $4,98 \mathrm{~mm}$ dia $^{-1}$ e evapotranspiração de $2,21 \mathrm{~mm} \mathrm{dia}^{-1}$ apresentando um saldo positivo de $2,77 \mathrm{~mm} \mathrm{dia}^{-1}$. Os dados mostram que as condições climáticas para o desenvolvimento da cultura foram adequadas, mesmo com um excesso de umidade, o qual não apresentou nenhuma limitação devido a boa drenagem do solo.
Tabela 1 - Influência da densidade de semeadura no rendimento de grãos (RG), no número de legumes por metro quadrado $\left(\mathrm{NL} \mathrm{m^{-2 }}\right.$ ), no peso de 100 grãos (PCG), no número de ramos por metro quadrado $\left(\mathrm{R} \mathrm{m}^{-2}\right)$, no número de nós do caule da planta (NP) e na estatura de plantas (EST) da cultivar de feijão comum Iraí, cultivada na safrinha de 2001, em Santa Maria-RS.

\begin{tabular}{lcccccc}
\hline $\begin{array}{l}\text { Densidade } \\
\left(\mathrm{plt} \mathrm{ha}^{-1}\right)\end{array}$ & $\begin{array}{c}\mathrm{RG} \\
\left(\mathrm{kg} \mathrm{ha}^{-1}\right)\end{array}$ & $\mathrm{NL} \mathrm{m}^{2}$ & $\begin{array}{c}\text { PCG } \\
(\mathrm{g})\end{array}$ & $\mathrm{R} \mathrm{m}^{2}$ & $\mathrm{NP}$ & $\begin{array}{c}\text { EST } \\
(\mathrm{cm})\end{array}$ \\
\hline 200.000 & 1831 & 231,25 & 42,3 & 166,25 & 7,05 & 25,25 \\
300.000 & 1993 & 238,75 & 41,4 & 180,0 & 7,04 & 29,36 \\
400.000 & 1898 & 263,75 & 40,8 & 225,0 & 7,14 & 28,48 \\
500.000 & 2110 & 276,25 & 40,9 & 205,0 & 6,41 & 25,63 \\
MÉDIA & 1958 & 252,50 & 41,35 & 194,10 & 6,91 & 27,18 \\
CV (\%) & 7,74 & 17,46 & 3,81 & 17,18 & 18,5 & 8,49 \\
\hline
\end{tabular}

É licito pensar que, em condições ambientais favoráveis, como neste caso, as populações mais baixas tenham sido favorecidas, permitindo um desempenho semelhante às altas populações, visto que os materiais de hábito de crescimento determinado apresentam limitações na sua plasticidade.

DUARTE \& ZIMMERMAN (1994), ao analisarem a adaptabilidade e estabilidade de genótipos de feijoeiro, determinaram que a maioria dos genótipos testados mostrara-se menos responsivos à medida que as condições ambientais melhoraram, fato que pode explicar os presentes resultados. As condições de cultivo podem ter sido tão favoráveis que não permitiram à cultivar responder às modificações no arranjo de plantas. BISOGNIN et al. (1997) assinalaram que a indicação de uma época de semeadura deve ser acompanhada de uma recomendação de cultivares específica e de um manejo adequado a esta situação.

A literatura apresenta exemplos de resposta do feijoeiro ao arranjo de plantas (ALMEIDA \& SANGOI ,1994; GUIDOLIN et al., 1998; ALCÂNTARA et al., 1991). No entanto, nenhum destes autores indicou o nível de condições em que seus experimentos foram realizados.

O número de legumes planta ${ }^{-1}$ (Figura 1A) mostrou uma associação linear negativa com a população de plantas, sendo de 10,5 legumes planta-1 para 200 mil plantas ha $^{-1}$ e 5,1 legumes planta ${ }^{-1}$ para 500 mil plantas $\mathrm{ha}^{-1}$. Essa tendência já havia sido demonstrada por AGUDELO et al. (1972) como uma resposta normal da espécie ao aumento do número de plantas por área. No entanto, não foi possível evidenciar diferenças significativas para o número de legumes $\mathrm{m}^{-2}$ (Tabela 1), sendo que para esta característica a média do experimento foi de 252. Conforme NIENHUIS \& SING (1985) o número de nós $\mathrm{m}^{-2}$ está altamente relacionado com o rendimento, provavelmente por estar diretamente relacionado ao número de legumes $\mathrm{m}^{-2}$.

$\mathrm{O}$ número de grãos legume ${ }^{-1}$ (Figura $1 \mathrm{~B}$ ) também apresentou uma associação linear negativa com 


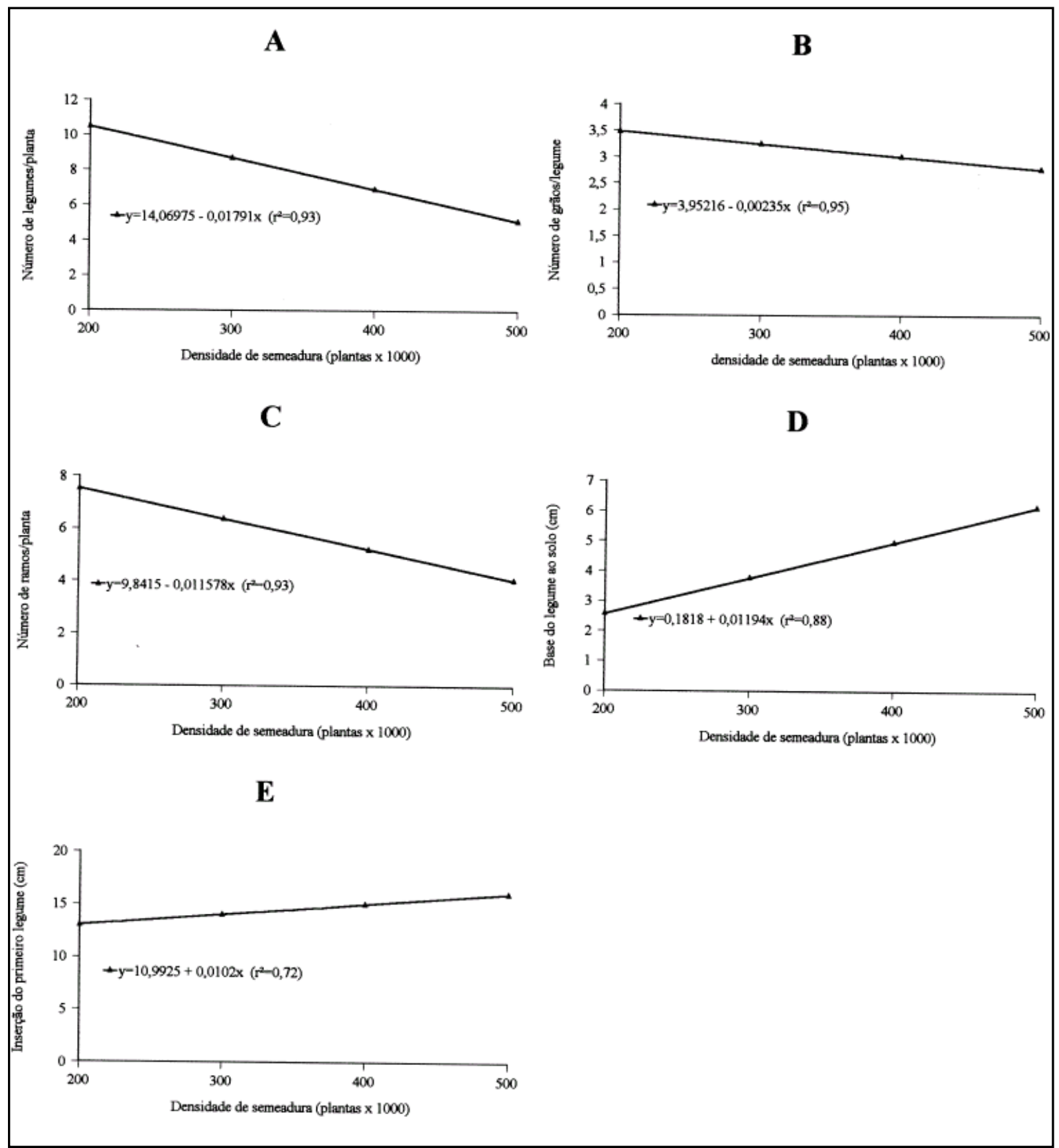

Figura 1 - Número de legumes por planta (A), número de grãos por legume (B), número de ramos por planta (C), distância (cm) do primeiro legume até o solo (D) e altura (cm) de inserção do primeiro legume (E) da cultivar de feijão comum Iraí em quatro densidades de semeadura, cultivada na safrinha de 2001, na localidade de Santa Maria-RS.

a população de plantas, ainda que a diferença entre o maior e o menor valor no intervalo analisado tenha sido de aproximadamente 0,5 grãos legume ${ }^{-1}$.

O peso de 100 grãos (Tabela 1) não apresentou diferença significativa, sendo que a média do experimento foi de $41,3 \mathrm{~g}$, enquanto a média para a cultivar, conforme CEPEF (2000), é de 38,4 g, evidenciando que as condições do experimento não alteram as características comerciais do grão.

$\mathrm{O}$ número de nós caule ${ }^{-1}$ e a estatura de plantas (Tabela 1) não apresentaram diferenças significativas, sendo as médias do experimento de 6,9 nós caule ${ }^{-1}$ e $27,2 \mathrm{~cm}$ de estatura. NIENHUIS \& SING (1985), analisando o comportamento de quatro 
cultivares do tipo I também não encontraram variações para esta característica entre 50 e 300 mil plantas ha-1, demonstrando que as plantas deste hábito de crescimento apresentam escassa capacidade plástica, modificando pouco seu padrão de crescimento em função da densidade de plantas.

$\mathrm{O}$ número de ramos planta $^{-1}$ (Figura $1 \mathrm{C}$ ) diminuiu com o aumento da densidade de semeadura. Por outro lado, o número de ramos $\mathrm{m}^{-2}$ (Tabela 1) não diferiu entre os tratamentos, apresentando um valor médio de $194 \mathrm{~m}^{-2}$. Dados similares foram encontrados por THOMÉ (1982) com a mesma cultivar. Segundo este autor, o número de ramos planta ${ }^{-1}$ aumenta nas menores densidades devido à menor competição por luz, água e nutrientes, porém tendendo a estabilizar por unidade de área, devido à pouca plasticidade.

As medidas da altura da base do primeiro legume ao solo (Figura 1D) e da inserção do primeiro legume ao solo (Figura 1E) reagiram positivamente ao aumento da densidade de semeadura. No entanto, mesmo na maior densidade, não alcançaram valores que possibilitassem a colheita mecanizada.

MASCARENHAS et al. (1966) determinaram que o melhor arranjo de plantas para a cultivar Goiano Precoce (tipo I) seria de 500 mil plantas ha- ${ }^{-1}$ com espaçamento entrelinhas de $0,20 \mathrm{~m}$, porém recomendam a utilização de 250 mil plantas ha ${ }^{-1}$ espaçadas $0,40 \mathrm{~m}$ por facilidade de mecanização das capinas e tratos culturais e redução de gastos com sementes. Esses critérios para seleção de um arranjo de plantas para as cultivares do tipo I, podem não ser os mais adequados, visto que rendimento de grãos, velocidade de fechamento do dossel, ocorrência de moléstias, possibilidade técnica de controle químico de insetos, plantas daninhas, nível de mecanização da lavoura e adaptação da cultivar às condições de cultivo se apresentam hoje como critérios mais recomendáveis, pois abordam o problema de forma holística. O gasto de sementes certamente tem um ônus menor do que sucessivos controles com capinas e/ou herbicidas, justificando o aumento da densidade quando esta não comprometer os demais fatores.

\section{CONCLUSÃO}

A cultivar Iraí semeada na safrinha não apresenta variação no rendimento com a população de plantas variando de 200 a 500 mil plantas ha- ${ }^{-1}$.

\section{REFERÊNCIAS BIBLIOGRÁFICAS}

AGUDELO, D.O, HERNANDEZ L.A., BASTIDAS, R.G. Efecto de la densidade de plobacion en el rendimiento y otras caracteristicas agronomicas del frijol (Phaseolus vulgaris L.). de crescimiento voluble y arbustivo. Acta agronomica, Palmira, v.22, p.39-50. 1972.
ALCÂNTARA, J.P. et al. Avaliação de cultivares de feijoeiro (Phaseolus vulgaris L.) em diferentes densidades de semeadura e condições de ambiente. Ciência e Prática, Lavras, v.15, n.4, p.331-428,1991.

ALMEIDA, M.L. de.; SANGOI, L. Manejo de cultivares de feijão de diferentes Habitos de crescimento no planalto catarinense. Rendimento de grãos. Ciência Rural, Santa Maria, v.24, n.3, p.513-517, 1994.

BRASIL. Ministério da Agricultura e do Abastecimento. Instituto Nacional de Meteorologia - INMET. Oitavo Distrito de Meteorologia - $8^{0}$ DISME. Normas climatológicas obtidas com dados do período 1961-1990. Brasília, 1992. 84 p.

BISOGNIN, D.A. et al. Desempenho de cultivares de feijão em semeadura tardia no planalto catarinense. Ciência Rural, Santa Maria, v.27, n.2, p.193-199, 1997.

CHAGAS, J.M.; VIEIRA, C.; BÁRTHOLO, G.F. Comportamento da cultura do feijão (Phaseolus vulgaris L.) no outonoinverno. Revista Ceres, Viçosa, v.30, n.169, p.224-231. 1983.

CEPEF. Feijão: recomendações técnicas para o cultivo no Rio Grande do Sul. Santa Maria : Pallotti, 2000. 80 p.

CROTHERS, S.E.; WESTERMANN, D.T. Plant population effects on the seed yeld of Phaseolus vulgaris L. Agronomy Journal, Madison v.68, n.6, p.958-960. 1976.

DUARTE, J.B.; ZIMMERMANN, J.O. Adaptabilidade e estabilidade de rendimento de genótipos de feijoeiro comum. Pesquisa Agropecuária Brasileira, Brasília, v.29, n.1, p.2532, jan.1994.

EMBRAPA. Centro Nacional de Pesquisa de Solos (Rio de Janeiro, RJ). Sistema Brasileiro de Classificação de Solos. Brasília : EMBRAPA Produção de Informações; RJ: EMBRAPA Solos, 1999. XXVI, 412p.

GUIDOLIN, A.F. et al. Efeito do arranjo e da população de plantas sobre o crescimento do feijão em semeadura tardia. Ciência Rural, Santa Maria, v.28, n.4, p.547-551, 1998.

NIENHUIS, J.; SINGH, S.P. Effects of plant density on yeld and architectural traits in dry beans. Crop Science, Madison, v.25, n.4, p. 579-584. Jul.-ago. 1985.

MARTINOTTO, V. et al. Ensaio estadual de variedades. In: REUNIÃO TÉCNICA DO FEIJÃO, 16., 1982, Porto Alegre. Ata... Porto Alegre : IPAGRO, 1982. p.150-153.

MASCARENHAS, H.A.; IGUES, S.A.; VEIGA, A.A. Espaçamentos para feijão Goiano Precoce. Bragantina, v.25, p. 51-53, 1966.

MOREnO, J.A. Clima do Rio Grande do Sul. Porto Alegre: Secretaria da Agricultura, Diretoria de Terras e Colonização, Secção de Geografia, 1961. 46p.

ROLAS. Recomendações de adubação e de calagem para os estados do Rio Grande do Sul e de Santa Catarina. 3. ed. Passo Fundo : SBCS-Núcleo Regional Sul, 1994. 224p. 
STORCK, L., LOPES, S.J. Experimentação II. 2. ed. Santa Maria: UFSM, CCR, Departamento de Fitotecnia, 1998. 205p.

THOMÉ, V.M.R. Crescimento, desenvolvimento e rendimento de grãos de uma cultivar de feijoeiro de hábito de crescimento arbustivo determinado, em função da época de semeadura, espaçamento entre linhas e densidade de plantas. 1982.139 p. Dissertação (Mestrado em Agronomia) - Curso de pós graduação em Agronomia, Universidade Federal do Rio Grande do Sul. 